SHS Web of Conferences 6, 02005 (2014)

DOI: $10.1051 /$ shsconf / 20140602005

(C) Owned by the authors, published by EDP Sciences, 2014

\title{
The Change Path of Agricultural Production Outsourcing
}

\author{
Zhang Juan ${ }^{\mathrm{a}}$ \\ Business School of Nantong University, 226019 Nantong Jiangsu, China.
}

\begin{abstract}
The system of agricultural production outsourcing is a breakpoint for the development of agriculture and immigration worker's urbanization. The analysis based on framework of the Institutional Change reveals that as a whole, the outsourcing system of agricultural production improves the welfare of society effectively. To some extents, it also can solve the problem of food security. The rural transferring labor-forces who realize the institutional change in the initial stage are is the first Action Group to gain the potential benefits. Local governments are a breakpoint of induced institutional change, which find potential benefits and then change the role of system changes. The central government is in dominant statue during the whole change. The outsourcing is a kind of improvement to the Family Contracted System, also an adaption to an imperfect Chinese rural social security. So the outsourcing has a positive meaning in the rural area.
\end{abstract}

Keywords. Institute Economics; agriculture production outsourcing; specification analysis institute change path

China's National Bureau of Statistics reported that the number of Chinese migrant workers reached 252780000 in 2011 , which increased by $4.4 \%$ on the basis of 2011 . Due to various reasons, these migrant workers are not willing to give up the right to their contracted land, though in reality they are unable \& unwilling to work on the land. Therefore, some places, particularly in coastal area, farming is abandoned or roughly managed. In order to increase the land use efficiency and deal with the living cost increase caused by food price increase, there are special individuals or organizations in the countryside to provide the service from planting to harvesting during the agricultural production. Therefore the migrant workers can sub-contract their land to others. This is the agricultural outsourcing system taking shape from the existing rural operation system, the social security system and the urbanization of migrant workers. The general outsourcing service emerged in Adam Smith's age. International outsourcing service also existed from an early age, for example, the traditional international logistics industry. The modern outsourcing service started from 1980s, the theoretic icon was the theory put forward by Prof. Drucker, the famous managerialist, that in any enterprise, any work that only supplies backup support \& does not create direct production value should be outsourced. In China, the outsourcing service started early with different technical contents and levels, covering the high low-end services. In 1980s and 1990s, with the wave of IT industry, research on outsourcing also increased, including the significance of outsourcing, economic analysis, developing characteristics, and affecting factors, outsourcing system, organizational management and specific empirical analysis. Generally speaking, outsourcing service reduces the production cost and increases the profit margin by taking advantage of specialization of work, resource endowment, economies of

\footnotetext{
a Corresponding author: nt590590@126.com
} 
scale and low labor cost. As a systematic form, outsourcing has been applied in agricultural production in recent years with rapid growth. Outsourcing in agricultural production has its similaries and differences from other industries. There are few academic researches on agricultural outsourcing; therefore the application in agricultural production still lacks theoretical support. In this case, the paper analyzes interest changes of relative bodies from aspects of demand and supply using Institutional Change Theory. Its purpose is to provide suggestions and put forward opinions.

\section{A theoretical hypothesis-agricultural production outsourcing is a breakpoint for the development of agriculture}

The late 20th century, with the development of IT industry, service outsourcing industry was developed rapidly. The outsourcing of agricultural production appeared in China's eastern coastal areas in the past few years with rapid development momentum. Agricultural production outsourcing and the international service outsourcing are different in background but similar in theoretical connotation, operation mechanism and decision-making objectives. The rural transferring labor-force outsources the contracted land planting to the untransferable force or service institution under the background of the high planting cost and opportunity cost with which the transferring labor-force plants the contracted by itself. In this context, the labor force will outsource contracted land. And then agricultural production outsourcing system came into being. If the contracted lands are in situation of barren and semi-barren for a long time, it would aggravate the food security and other social problems. Under the background of the current rural operation system and rural social system, agricultural production outsourcing system can allocate land and labor resources effectively, which is a breakthrough point of agricultural development at present. This is the specific use of specialization of labor division, economies of scale, and theory in agriculture production in agricultural production, whose purpose is to pursue profit from the specialization of labor division and economies of scale, and to reduce the cost of labor force and resources.

\section{The analysis framework of the institutional change}

There are many institutional change theories, including analysis of the affecting factors. For example, Lu Xianxiang thinks that there are four factors affecting the demand including the relative price of product, the constitutional order, technology, market scale. The New Institutional Economics, edited by Lu Xianxiang and Zhu Qiaoling, thinks the main body of institutional change has the central, local government, various economic and social organization, and rural family. The paper analyzes the demand of agricultural production outsourcing from the perspective of stakeholders involved by the institutional change process. On the basis of the analysis, it studies the path of institutional supply further. Overall, the agricultural production outsourcing institution arrangement increases social welfare in the whole, is not Caldor Hicks Improvements, but Pareto's. The main body affecting the demand of agricultural production outsourcing system has governments, service cooperatives, and package of farm households. The article researches benefit changes of each demand subject before and after the execution of the outsourcing system.

\subsection{The demand of institutional change}

Rural labor transfer occurred on a large scale. Statistical data of Jiangsu Nantong showed that the transfer rate in Jiangsu Nantong in 2012 reached 75\%, and was as high as 78\% in Qidong. But for various reasons, even if the rural transferring labor-forces have stable jobs in the city, they are not willing to give up the contracted land rights. However, agriculture, a highly seasonal industry, needs to invest a lot of manpower in the planting and harvesting seasons. This gives a dilemma to the rural transferring labors. Farmer's professional cooperatives and its service have been developed since 2007, and the prices of agricultural products have been soaring, which provide the conditions for the 
emergence and development of Agricultural production outsourcing system. With the further transfer of rural labors, especially, the new generation of migrant workers drifts rural life away further and further, the demand of agricultural labor outsourcing increases obviously. Driven by the demand, outsourcing as a service supply arises at the right moment.

\subsection{The changes of government interest}

Governments, as the representatives of the whole social welfare, supply policies to promote agricultural production outsourcing, which can enhance the welfare of the whole society. Agricultural production outsourcing system can make use of scarce land resources effectively and solve the rice bags, vegetable baskets and other issues for the project, "governors in charge of the rice bag, mayors vegetable basket", which is undoubtedly a great contribution, also conforms to the modern agricultural development goals, and thus receives a welcome at all levels of government. It can be verified by preferential policies from governments. Picture 1 is a diagram of the change in social welfare before and after the implementation of agricultural production outsourcing system. The horizontal axis is the system quantity $\mathrm{Q}$, vertical axis for the price $\mathrm{P}, \mathrm{CA}$ as the system demands, $\mathrm{S}_{1}$ for the system supply before outsourcing and $S_{2}$ for outsourcing system supply. System demand shifts to right from CA to $\mathrm{BD}$, which says outsourcing requirements increase in agricultural production services. In picture1, system supply is comparatively special in that $S_{2}$ starts from $E_{1}$, because outsourcing system supply increases the system supply on the basis of the equilibrium of the original system demand and supply in order to meet the demand of transfer of labor force households. As can be seen from the picture1, consumer surplus of outsourcing system requirements is $\mathrm{SCE}_{1} \mathrm{P}_{1}(\mathrm{~S}$ is the area, the same below) and producer surplus is $\mathrm{S}_{1} \mathrm{E}_{1} \mathrm{~F}$. After outsourcing system requirements, but no system supply, consumer surplus is $\mathrm{S} \mathrm{DE}_{2} \mathrm{P}_{2}$ and producer surplus is $\mathrm{S}_{2} \mathrm{E}_{2} \mathrm{~F}$. While outsourcing has system supply, consumer surplus is $\mathrm{S} \mathrm{DE}_{3} \mathrm{P}_{3}$ and producer surplus is $\mathrm{S} \mathrm{FE}_{1} \mathrm{E}_{3} \mathrm{P}_{3}$. Comparison of before and after the emergence of outsourcing system, the welfare of the whole society have changed, consumer surplus increasing $\left(\mathrm{SDE}_{3} \mathrm{P}_{3}>\mathrm{SDE}_{2} \mathrm{P}_{2}\right)$, producer surplus increasing $\left(\mathrm{S} \mathrm{FE}_{1} \mathrm{E}_{3} \mathrm{P}_{3}>\mathrm{SP}_{2} \mathrm{E}_{2} \mathrm{~F}\right)$ and the welfare of the whole society increasing by $\mathrm{SE}_{1} \mathrm{E}_{2} \mathrm{E}_{3}$.

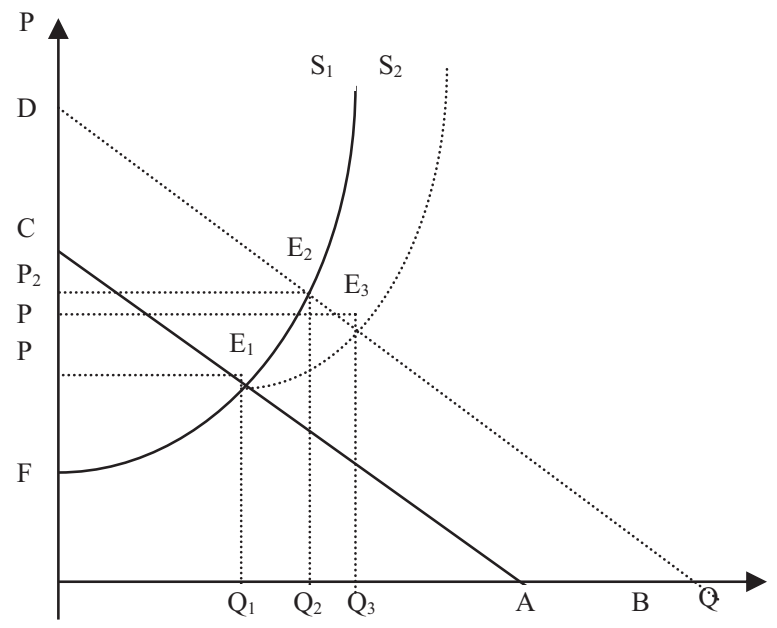

Figure 1. The change of social welfare before and after the implementation of agricultural production outsourcing.

\subsection{The changes of outsourcing household's interest}

Before and after the implementation of the outsourcing system, the interests of outsourcing demanders also changed. As the transferring of labor force do not outsource agricultural production, they will 
have two options: to give up farming, which is to let the contracted land wasted or in a extensive management, but the increase of agricultural products' price makes living cost up over these years; or farming by themselves, which as the subjective of market is considered that it will make high opportunity cost comparing to the interest. The outsourcing of the several parts of production can not only obtain agricultural products, reduce the cost of living, but also reduce the opportunity cost of labors and the cost of their commute. Through the comparative of cost and interest, the transferring-labor family will find that the increased interest and decreased cost is higher than the increased service cost, so it increases the outsourcing interest. After analysis of the comparison of cost-benefit, the outsourcing of labor conforms to the value that economic benefit is the most important, so households choose the outsourcing in behavior.

\subsection{The changes of service cooperative's interest}

The transferring labor contracts the outsourcing of one or several parts of the production with service cooperatives, which provide services for them, whose purpose is the pursuit profits of cooperation and scale economy. Profits mainly come from three aspects. The first one is in the pre-production link; unified purchase of capital goods, such as seeds, pesticides, fertilizers and others decreases the irrational use. With the expansions of purchase, costs will have a significant decrease. In Hebei Province, more than 90 percent of cooperatives uniformly provide means of production ${ }^{[13]}$. Secondly, the costs of employment and use of agricultural equipments are reduced. Thirdly, the cost of products in the after-production link also decreased, which causes the decrease of information searching and monitoring cost.

\subsection{The changes of servicing family's interest}

Part of the rural labor forces is proficient in cultivating. In the opposite, the other part is hard to transfer to be fully employed. But they can provide specialized services for agricultural production outsourcing by joining the service cooperatives after training, which reduce their opportunity cost and increases revenue. After agricultural production service' training and practicing, they also improve the skills which is demanded in production links, reduce the probability of making troubles out of nothing. From this point, the outsourcing services have social functions to some extents. Besides, the farmers who is proficient with cultivating usually owns agricultural machine. Using machines to service other outsourcing farmers in the service institution will enhance the efficient utilization of capital to increase income and decrease depreciation cost.

Service institutions, outsourcing farmers and outsourcing accepted farmers share the mutual benefits. North thought that the subjects based on the interdependence are in the demand of reciprocity system for the benefit from division of work and surplus of cooperation which can be only achieved with reciprocity system.

\section{The institution changing path}

The outsourcing system, to a large extent, can promote the development of agricultural production while making various market subjects share the surplus interests. But China's reforming history demonstrates that all reforms are bottom-up, induced by interests in rural, whose primary form of expression is the public choice by peasants' will, and there is no written laws to obey, which only can exist in the form of informal constraints, be the rules of the game of rural economic system changes during the initial processes. Only when the cost of system's innovation recognized by the central government and receive the afterwards admission, informal constraints can gradually "formatted" as the legal provisions in the formal constraints morphology. ${ }^{[14]}$ Related studies showed that the realizable change path is gradually shift from supply-led reform at the beginning to the middle of the diffusion type, the ultimate transition to the demand-induced, with the gradual establishment of exclusive rights in the centralized and planned economy nation who is likely to succeed in a gradual 
transition to a market economy. ${ }^{[15]}$ The change process of outsourcing system, combined with the above the views, the study considers that the outsourcing institutional arrangements can be divided into three stages, demand-induced, middle -proliferation and government-led.

The outsourcing is a down-up changing process. The production barriers force every market subjects to look for new institutional arrangements. The first action-group is the transferring labor force. The outsourcing which they pursuit is a new institutions on the basis of the original, show features of margin and improvement which is typical to demand-induced institutional change. Economics think that supply is for demand. Farmer's professional cooperatives bring up kinds of different service cooperatives, lead the development direction and promote the producing and development of outsourcing system.

In the condition of top-down guided institutional change still exists, demand-induced one can meet barriers. It needs to get a concession from the power center. Thus local governments are often a breakpoint for demand-induced institutional change ${ }^{[14]}$. The local governments can not only satisfy the needs of the microscopic subjective, seeking the maximum benefits under the unbalanced condition, but also can realize the way of institutional change to look for the maximum rent of national monopoly ${ }^{[15]}$.Under the background of powerful governments for a long time in China, farmers, the cooperative and other market main subjectives are difficult to be the negotiator of the central government directly. And institutional arrangements are also hard to be recognized by the central governments. The local governments are between farmers and the central government. Through analyzing and evaluating the demands of the outsourcing and realizing the considerable potential profits about the system, the local governments will recognize the system internally and promote the formation and development of outsourcing system externally by using tests, setting examples, motivating and other administrative power within the areas. For example, the local government uses preferential policies to promote the scale operation, the development of the service, meeting the demand of the outsourcing. Then the local government can use formal or informal measures to affect the government at a higher level. The outsourcing arrangements are transmitted, analyzed and approved again and again between the governments at lower and higher level. The institutional change begins the spread between different levels of government, and the system supply spreads into the middle stage. The local governments get involved in the system supply which have an intervention effect, and are the secondary action-group of the outsourcing. The central government decides whether the outsourcing can be a part of the service of agricultural production, and determines the direction and the path of institutional change. Therefore, the main body of supplies about the outsourcing system eventually is the central government.

In the earlier paragraph, there are several stages in the evolution of the path about agricultural production outsourcing. However, there is no natural segmentation between these stages in practice, and these phases exist at the same time in different areas. The path in developed regions can provide references for other developing areas so that further steps can be taken to improve the agricultural social service system.

\section{Policy implications}

The research reveals that the following aspects should be considered to promote the development of outsourcing.

Innovating and improving the supporting institutional system. The emergence of the outsourcing system is not only an adaptation, but also a kind of improvement to china's rural operation system. Under the premise of stable rural basic management system, the first thing to improve the outsourcing is consummating the supporting institutional system which is associated with it such as the rural land system, the social security system, and other systems. What's more, it is necessary to cancel the household registration system and reduce welfare differences between urban and rural areas fundamentally in order to push the process of urban-rural integration. As the same time, the outsourcing can be gradually developed into the large-scale farming in China.

Developing the professional service cooperatives. It is one of the effective promoters to the 
outsourcing. In the period of social economy transforming, it is necessary to exert farmers' intelligence and capacity and implement various preferential policies ,such as giving greater support about land, water and tax, and increasing subsidies of agricultural machinery for raising the level of mechanization about scale operation and production efficiency. Through preferential policies, the professional service cooperatives can promote services.

The local governments act as catalysts for collaborative services. The local governments use their influences to form and push the outsourcing, strengthen propaganda, and actively create a good atmosphere for the outsourcing. In order to raising awareness of the members in the service, the governments organize them to visit, so that members can make preparations to set up the service. In addition, the local governments encourage the agriculture sectors to train the people who undertake the outsourcing. The agriculture sectors ought to establish service standards which provide solutions to solve the differences in service.

Remodeling the social service system of agricultural production. The outsourcing system with service cooperatives is a significant part of agricultural social service system. Senior governments are supposed to reform the public service organization within the system, and introduce multi-dimensional main subjectives to participate in the market competition. Afterwards, they encourage the docking of technology between scientific research institutions such as universities and the service cooperatives. To establish and improve the commercialized rural service system, the senior governments should encourage low-level governments to cultivate more and better services which are suitable for local economy and social needs, and pay attention to the relationship between the various services. As a result, the governments can be able to provide complete services for agricultural production.

\section{References}

1. China National Bureau of Statistics, Chinese migrant workers more than 250 million [N]. www.zaobao.com, 2012.04.27.

2. Guo Xiangyu. The common features of agricultural socialized service system development and its enlightenment in developed countries [J]. Issue of Agricultural Economy, 1999 (7) : 10-14.

3. Hu Hengyang. Construction emphasis and system reform on rural infrastructure [J]. Rural Work Communication, 2006 (11): $38-39$.

4. Lu Feng. The economic analysis on the service outsourcing: product specialization perspective [M]. Beijing: Peking University Press, 2007:12-23.

5. Li Yueyun, Xi Qinggao. On service outsourcing: international trend and domestic development [J]. Journal of Nanjing Agricultural University (Social Science Edition), 2007(7 ):3.

6. You Lina. Study on the service outsourcing in Economics [D]. Southwestern University of Finance and Economics, 2010 (6) : 23-30.

7. Liu Chong. Strategy chooses in the development of service outsourcing from India service outsourcing development factors [J]. Foreign trade 2010 (5) : 115-117.

8. Kong Xiangrong. Institutional factor analysis of the development of international service outsourcing [D].Shandong University, 2010 (6) : 53-61.

9. Liu Zhengchi. Research on governance model and operating mechanisms of service outsourcing [D]. Hunan University, 2009 (10) : 33-61.

10. Xuyong. Service outsourcing: a theoretical interpretation and empirical research [D]. Jilin University, 2010 (12) : 75-79.

11. Lu Xianxiang. New Institutional Economics [M], Wuhan:Wuhan University Press, 2003:154-165.

12. Lu Xianxiang, Zhu Qiaoling. New Institutional Economics [M]. Beijing: Peking University Press, 2010:136-145.

13. Chen Xiaohua. Major issues and advance measures in the development of farmers' professional co-operatives [J]. Journal of Qingdao Agricultural University (Social Science),2011. (8) 1-7. 
14. Yang Ruilong. Three-stage theory of way conversion of Institute changes in China---Study on Institute innovation behavior of local government [J]. Economic Research Journal, 1998 (1) : 3-10.

15. Yang Ruilong,Yang Jijing. Gradual institutional change model in the style of step by step--- study the role of local government in institutional change[J]. Journal of Economic Research, 2000 (3) : 24-31. 